\title{
War Stories
}

\section{Michael Stillman, MD}

Boston, MA, USA

First we vent.

"That meeting was ridiculous."

"Sounds like it."

"Institutional politics don't ever change."

"Preach!"

Or:

"I'm so tired I feel like a husk."

"Well, I could barely walk when clinic ended.'

"We're not talking about you, Sweetness. This is me.

It's like I got fed through a wood chipper."

Greens are chopped. Wine is gulped. The table is set.

The furrow in my brow softens.

And we sit.

Steve and I used to eat dinner in bed, side-by-side, facing the television. That strategy conserved energy, but we dropped it several years back in favor of old-fashioned conversation.

Then we list. Our war stories from the day.

"It was the worst vaginitis I've seen. Just. . .unspeakable."

Steve chortles sympathetically, Rioja sputtering from his nostrils.

"He had a pressure ulcer the size of my fist, and orthostasis so bad he couldn't sit up."

Hemorrhoids, dyspepsia, lumbago.

Breast cancer in a thirty year old.

The dreaded chronic pelvic pain.

There is healing in this re-telling. An expulsion, of sorts. A day's stressors washed away.

And, finally, we reflect.

"I saw this new patient today. Adorable. Gay. The whole time he was referring to another man. 'I picked Andy up from each of his three scopes. He'd better return the favor.' And, 'Andy told me to make sure I asked about my pressure, and to get my prostate checked.'

"So I asked this guy whether he and Andy were a couple and he just chuckled. 'Nope,' he said, 'we've been best friends since high school. Moved out West together then back. Seen each other through bad relationships and tragic haircuts. But we've never even thought thought about dating.",

Steve and I muse on families we choose. The people without whom we're born but on whom we most depend. On the shocking improbability of finding one another in a vast and lonely world. It's a conversation we've had before, but we enjoy delving into it again.

We reflectively stab at our salads, and Steve resumes the ritual.

"I went to a patient's funeral this afternoon. He and his wife were best friends - childless and interdependent. And I was certain she was going to fall apart. Just throw herself on the coffin.

"But when she stood at the lectern, she was absolutely. . .heroic. Back straight, eyes blazing, defiant. Magnificent. She made eye contact with us, Mike. Like she was daring us to pity her. She wasn't a wet rag but a steel rod. It was breath taking."

So we chat about resiliency and unanticipated strength. The unpredictability of who will and will not fold. About the ways in which we surprise one another, and how blessed we are to have the capacity for surprise.

By now we've finished eating and are ready to clean the kitchen.

"One more story, Stevie. I really need your help with this one."

J Gen Intern Med 27(12):1728-30

DOI: $10.1007 / \mathrm{s} 11606-012-2114-5$

(C) Society of General Internal Medicine 2012 
He settles back down.

"One of my favorite patients died over the weekend, but I just found out today. His wife called to let me know. He had a heart attack, went to a local emergency room, was in failure. His family gathered in the unit and he died."

“Tough.”

"Yeah, tough."

"Steve, thirty seconds before he died, his wife leaned over and whispered in his ear, "Honey, how are you feeling?' And he said, 'I'm dead, Ma.'”

"And then he died?"

"And then he died."

Neither of us knows quite what to say about that. The questions and implications are imponderable. Do we knowreally know with certainty - when we are about to die? If so, how? And what does it feel like, both the awareness of impending death and death itself? Fear? Ecstasy? Calm? Like slipping off to sleep while reading, wanting to stay awake, but knowing you can't?

And can we choose our moment of death? Unhinge ourselves and let go? What that patient said: "I'm dead."

We go to our room to watch television.

People often ask Steve and me what it's like being physicians. Or if we enjoy our work.

My flip answer (Steve is kinder than I) is that it is intolerable.

"Can you imagine how paranoid I've become? How fixated on even the most niggling symptom? How I worry?"

A knowing nod drives my worst instincts.

"Or what it's like to wake each morning," I'll bray, "having only bowel dysfunction, anxiety, and low back pain to look forward to?"

Sustained concern sends me in for the kill.
"I'm surprised I haven't quit!"

This assessment, of course, is untrue, but I keep it in my quiver for emergency use. Generally to pry myself from chinwaggers at cocktail parties, or if I sense the follow-up question will be a request for medical advice.

A second answer-which is factual but shallow-is that it is exhausting. We wake most days at an unjust hour, tire half way through "Glee," and have never found energy to audit the courses or attend the lectures we always thought we would. We both keep notepads at our bedside to keep track of uncompleted tasks, and often reach for them just as we're falling asleep or first thing in the morning. The work of caring for patients, it seems, is without end.

Our real feeling, however - the contemplative answer-is that practicing medicine is a gift.

Early in our careers, we were consumed with building clinical skills, so dinnertime conversations were more about tapping joints or cracking cases than being spiritually and philosophically challenged by our work.

As we've grown older, however, we've become more interested in patients' stories, as they lead us to explore how people inter-relate, cope with loss, brave intimacy, and face insecurity and death. Struggling with these "big" questions - and Medicine demands that struggle of us allmakes us broader and more insightful people. We are grateful for the challenge.

Steve and I also feel lucky to be a physician couple, as each of our work is familiar to the other. Sharing our "war stories" at dinner allows us to challenge and re-explore one another's beliefs, and in that way has become integral to the fabric of our relationship. Our work has made us a stronger unit.

It's bedtime now, and I've put my book away.

"Oh, my God, Stevie. I almost forgot to tell you."

"What?"

"I saw this guy today who kept getting urinary tract infections. And I worked him up and down and couldn't figure out why, so I sent him to a urologist."

"OK." 
"He went to him and told him he had some back pain, then wound up with pyelo two weeks later. So he wrote this letter to everyone. Ripping the urologist to shreds. His partners, his CEO, his CMO. Probably his PAs, too. He sent me a copy of it. It was fierce."

"Why do you think he's such an angry person?"

"A very deep question, Cutie. We'll take that one up tomorrow."
"Goodnight, then, Sweet."

"Goodnight."

Corresponding Author: Michael Stillman, MD; 720 Harrison Avenue, Suite 7600Boston, MA 02118, USA (e-mail: Michael. stillman1972@gmail.com). 